\title{
La recepción del pensamiento de Ortega y Gasset en la obra de Olivér Brachfeld
}

Virgili Ibarz Serrat Universitat Ramon Llull,

Barcelona, España

\author{
Recibido: 9 de julio del 2018 / Aceptado: 20 de julio del 2018 \\ doi: 10.26439/persona2018.n021.3016
}

\begin{abstract}
En 1931, Olivér Brachfeld entrevistó a Ortega y Gasset para la revista Internationale Zeitschrift für Individualpsychologie. En 1936, publicó Los sentimientos de inferioridad. En este artículo, a través de las sucesivas ediciones de la obra de Brachfeld, se analiza la recepción del pensamiento del filósofo español. Brachfeld piensa que Ortega y Gasset establece las bases para un análisis de la conducta fundado en los sentimientos auotestimativos, y formula una teoría de los sentimientos de inferioridad. Ortega y Gasset atribuye la soberbia a una reacción, a una disminución de nuestro ser, y la explica cuando dice que nuestro ánimo se revuelve y subleva contra una realidad que anula la estimación en que nosotros nos teníamos. Para ambos autores, el sentimiento de nivel da lugar a los sentimientos de inferioridad. El carácter de una sociedad dependerá del modo de valorarse a símismos de los individuos que la forman.
\end{abstract}

sentimientos de inferioridad / sentimientos de superioridad / Alfred Adler

\section{The reception of Ortega y Gasset's thoughts in the work of Olivér Brachfeld}

In 1931, Olivér Brachfeld interviewed Ortega y Gasset for the Internationale Zeitschrift für Individual-Psychologie magazine. His book, Inferiority feelings, was published in 1936. In this article, we analyze the reception of Ortega y Gasset's thoughts through the successive editions of Brachfeld's work. Brachfeld argues that Ortega y Gasset establishes the foundations for a behavior analysis grounded on the feelings of self-esteem, and formulates a theory of inferiority feelings. Ortega y Gasset claims that arrogance results from a reaction, a diminution of our being, and explains it when he states that our spirit revolts and rebels against a reality that destroys our self-esteem. For Ortega y Gasset and Brachfeld, the level of this feeling gives rise to inferiority feelings. Thus, the nature of a particular society will depend on the way its members value themselves.

\section{inferiority feelings / superiority feelings / Alfred Adler}

Correo electrónico: virgiliis@blanquerna.url.edu 


\section{INTRODUCCIÓN}

Olivér Brachfeld nació en 1908 en Budapest. No pudo acceder a la universidad de su ciudad porque el régimen de extrema derecha que gobernaba Hungría le prohibió cursar sus estudios. Por este motivo, se trasladó a Viena para estudiar en aquella universidad. Allí conoció a Alfred Adler y entró a formar parte de su círculo de seguidores más próximos.

En 1927 fue admitido en la Universidad Pázmány Péter de Budapest, donde se matriculó en Filología de Lenguas Románicas, y, en 1929, terminó sus estudios en la Universidad de Budapest. Entonces decidió hacer su tesis doctoral sobre Violante (12151251), la hija del rey de Hungría, casada con Jaime I (1208-1276), rey de Aragón y Cataluña, por lo que viajó a Barcelona.

Brachfeld regresó a Budapest para defender su tesis doctoral. Sin embargo, la corta estancia en Barcelona tuvo una influencia decisiva en su vida. Quedó muy impresionado por el ambiente cultural y científico que encontró. Esto, unido a la amabilidad y hospitalidad de la gente, le hizo tomar la decisión de establecerse ahí.

No obstante, tardó dos años para poder llevar a cabo esta determinación. Durante ese tiempo, cursó estudios en la Sorbona de París, donde obtuvo el Diplôme d'Études Supérieures, a la vez que asistía a otros centros universitarios, como el Institut Catholique y el Instituto de Psicología de París.

En 1931 llegó por segunda vez a Barcelona, donde rápidamente llamó la atención de los círculos intelectuales y culturales, en los que se introdujo con gran entusiasmo. Hemos de tener en cuenta que en ese año se proclamó la Segunda República en España y el ambiente cultural era extraordinario. A partir de 1931 empieza una de las épocas más felices de Brachfeld, que entonces tenía 23 años. Destacó como conferenciante muy prolífico: pronunció conferencias en centros culturales, ateneos, universidades, y organizó cursos y seminarios.

En estos actos públicos, escogía temas de literatura, historia, filosofía, sociología y, especialmente, divulgó la psicología profunda de la "nueva escuela vienesa", con sus dos principales representantes: Freud y Jung. Pero, de forma paralela, siempre quiso resaltar las teorías de la psicología individual, a cuyo autor, Alfred Adler, consideraba su maestro. En tal sentido, editó en Barcelona una revista cultural, titulada Europa, y creó un grupo de trabajo de psicología individual.

En 1936 estalló la guerra civil en España. Durante los primeros años, Brachfeld colaboró con los medios culturales de la República. En 1938 se casó con una joven barcelonesa. Sin embargo, a consecuencia del avance de las fuerzas franquistas sobre Barcelona, no tuvo otra opción que abandonar España y mudarse a París.

Durante la Segunda Guerra Mundial, en París era difícil desarrollar actividades culturales o académicas. En 1942 Brachfeld regresó a Barcelona y reemprendió las actividades a las que se dedicaba antes de la guerra civil, en los ámbitos de las conferencias, los artículos, las traducciones, las asesorías de editoriales, etcétera. Pero el 
ambiente era muy diferente al de la época republicana. Además, su gran aspiración siempre había sido dedicarse a las actividades académicas como profesor universitario.

En 1950, cuando ya habían pasado ocho años de su regreso de París, se hubo de rendir a la evidencia de que mientras estuviese vigente el régimen del general Franco no tendría la oportunidad de ser profesor universitario y decidió, finalmente, trasladarse a Venezuela. El Ministerio de Cultura y Ciencia de Venezuela le ofreció un contrato como profesor en la Universidad de Los Andes, en la ciudad de Mérida. Brachfeld participó en congresos en diversos países europeos, Estados Unidos y Canadá. En 1955 fue elegido presidente de la Sociedad Interamericana de Psicología, cargo que ejerció durante dos años, $y$, posteriormente, presidente de The Interamerican Society of Psychology.

En 1954 se suprimió su cátedra de la Universidad de Los Andes y regresó a Barcelona con su familia. Muy pronto vio que en España la situación continuaba igual. Durante un tiempo realizó diversos trabajos por encargo. Pero a finales de 1959 se vio forzado de nuevo a dejar Barcelona.

Brachfeld aceptó la invitación de la Universidad de Colonia, en la República Federal Alemana, esperando encontrar un ambiente menos hostil, más comprensivo que el de Barcelona. No obstante, al principio tuvo que afrontar reticencias y oposiciones por parte de las autoridades académicas. Uno de los problemas era el de su nacionalidad y documentación, ya que, después de haber vivido la mayor parte de los últimos 28 años en Barcelona, se encontraba sin nacionalidad y, por lo tanto, viajaba como un ciudadano apátrida. Para desplazarse tenía que utilizar uno de los llamados pasaportes Nansen, creados por las Naciones Unidas para los refugiados.

Finalmente, durante los seis años siguientes, mantuvo un contrato de profesor en la Universidad de Münster, en Westfalia, República Federal Alemana. Aquí impartió cursos y conferencias en diferentes instituciones universitarias, en centros de educación popular, en la radio y televisión. Continuó escribiendo numerosos artículos y colaboró en diarios y publicaciones científicas. Hemos observado que los temas que más aparecen en sus trabajos son los relacionados con la psicología social. El interés de Brachfeld por la sociología y su relación con la psicología adleriana se pone de manifiesto en sus artículos publicados en la Revista Internacional de Sociología.

El Ministerio de Cultura y Educación de la República Federal Alemana le ofreció incorporarse al Programa de Intercambio Cultural y Académico de científicos alemanes con el exterior, concretamente con Hispanoamérica. En el marco de este programa, fue a Bogotá, donde permaneció durante dos años (1965 y 1966), y posteriormente a Quito, durante el curso académico 1966-1967. En Quito, en plena actividad, el 2 de septiembre de 1967, murió inesperadamente a causa de un ictus.

\section{La obra de BrachFeld}

Durante la primera estancia en Barcelona, Brachfeld mantuvo una intensa colaboración con el editor Luís Miracle y con la 
editorial Apolo, que publicaban obras de psicología. Destacan la Teoría del psicoanálisis, de Jung, con traducción y prefacio de Brachfeld (Jung, 1935); El problema del homosexualismo y otros estudios sexuales, de Adler, con traducción y prefacio de Brachfeld (Adler, 1936); El sentido de la vida. Nuevas perspectivas de psicología individual, de Adler, con traducción de Brachfeld (Adler, 1941). Brachfeld seguía con atención las publicaciones europeas de los psicólogos alemanes, austriacos, suizos, etcétera. Tradujo obras de Piaget, Bühler, Künkel, Allers, Hochstädter, entre otros.

Además de su actividad como conferenciante, traductor $\mathrm{y}$ editor, Brachfeld es autor de diversos libros de psicología, entre los que destaca Los sentimientos de inferioridad (Brachfeld, 1936a [1970]), su obra magna. Ampliada y reformada, tuvo cuatro ediciones en España y tres no autorizadas en Hispanoamérica (México, Chile y Argentina). Ha sido traducida al inglés, alemán, francés, danés y sueco. Las dos últimas ediciones se han hecho en Alemania y en Hungría en el 2002. Más adelante analizaremos esta obra.

El año en que se produjo el estallido de la guerra civil en España, se publicó un nuevo libro de Brachfeld, El examen de la inteligencia de los niños (1936b), dedicado a Emilio Mira y López. En 1946, sale a la luz Psicología del jefe. Su formación y su misión (Carrard, 1946), traducido por Brachfeld; y, en 1949, La psicología y sus aplicaciones (Bernard, 1949), con un estudio preliminar de nuestro autor. Este libro fue publicado por la editorial Olivér
Brachfeld. En 1949, aparecen dos nuevas obras: Los complejos de inferioridad de la mujer. Introducción a la psicología femenina (Brachfeld, 1949a) y Cómo interpretar los sueños (Brachfeld, 1949b).

Ramón León ha analizado la figura y la obra de Brachfeld. En el artículo "Rumbo al Nuevo Mundo: cuatro psicólogos de Europa Oriental en la historia de la psicología en América del Sur" (1997), afirma que su vida y obra dan la impresión de una actividad ininterrumpida, plasmada en una inmensa cantidad de publicaciones. Sin embargo, precisa que estas son más bien estudios bibliográficos dedicados a la historia, la literatura, la sexología y la psicología adleriana, con una clara demostración de erudición.

León piensa que Brachfeld estaba más dotado para el trabajo bibliográfico minucioso y para la investigación histórica, literaria y psicohistórica que para el trabajo experimental y el estudio psicométrico. Sin embargo, aunque Brachfeld influyó poco en el desarrollo de la psicología como ciencia y como profesión en América del Sur, participó activamente en los primeros años de lo que hoy es la más importante asociación psicológica en América Latina, la Sociedad Interamericana de Psicología. León (2000) analiza el aporte de Brachfeld a la psicología a través de las páginas de la revista Internationale Zeitschrift für Individualpsychologie, y destaca que su enfoque en los artículos publicados es el histórico-literario.

Mestre y Carpintero (1988) examinan la introducción de las ideas de Adler en España. Ambos señalan que "Ortega y 
Gasset expuso breve, pero directa y claramente la sustancial coincidencia de su pensamiento con las líneas centrales de la psicología de Adler en una entrevista que le hizo en 1931 Olivér Brachfeld para la revista de psicología adleriana" (p. 57). Para estos autores, la proximidad y reconocimiento de Ortega y Gasset hacia la obra de Adler influyó también en el círculo de sus discípulos.

\section{La filosofía de Ortega y Gasset}

Ortega y Gasset nació en 1883 en Madrid, en el seno de una familia liberal relacionada con la prensa. Estudió en la Universidad de Madrid y completó sus estudios universitarios en Alemania. En 1929, dimitió de su cátedra en la Universidad de Madrid, por disconformidad con la dictadura del general Primo de Rivera, y prosiguió impartiendo sus clases en un teatro, lo que le aportó una gran popularidad. Fundó el periódico El Sol y la prestigiosa Revista de Occidente, donde se tradujeron al español las obras más significativas del pensamiento alemán. Se exilió al finalizar la guerra civil y no regresó a España hasta el final de la Segunda Guerra Mundial, en 1945. Permaneció en Madrid, al margen de las instituciones oficiales, hasta su muerte en 1955.

Ortega y Gasset sostiene que la actividad filosófica ha de partir de lo más inmediato. El sentido de nuestro yo lo podemos captar conjuntamente con el contexto en que mi yo, mi vida, tiene lugar. "Yo soy yo y mi circunstancia" dice una de sus ocurrencias más repetidas. "Yo" y "mundo" ("circunstancia") constituyen una unidad indivisible, donde cada una de las partes es imprescindible para entender la otra.

Para Ortega y Gasset, la verdad, el universo, la vida, están compuestos de infinidad de facetas que miran hacia un individuo. Cada persona, en combinación con su circunstancia, se encuentra en una posición en el mundo única e irrepetible. A cada uno de nosotros se le ofrece una perspectiva diferente de la realidad, se le manifiesta una de sus infinitas caras. No es solo una cuestión física del espacio (como ahora: estoy sentado a la derecha, y en frente tengo una perspectiva diferente de la computadora de la que tú tienes), ya que encima de la posición física se coloca la mental o intelectual e, incluso, la valorativa o moral.

Podemos deducir la importancia de la metáfora del espectador aplicada a la mente humana. Desde el observatorio de mi vida, soy un espectador privilegiado, no porque la realidad se ha de ajustar a mi visión, ni tampoco porque haya escenarios especiales desde los cuales nos sea posible captar la realidad como un todo o como es verdaderamente, porque estas posibilidades no son más que ilusiones. Lo que hace privilegiada la posición del espectador es su condición singular: para cada uno de nosotros solo hay un yo en $m i$ circunstancia.

Las obras más conocidas de Ortega y Gasset son Meditaciones del Quijote (1914), El espectador (1916), España invertebrada (1921), El tema de nuestro tiempo (1923), La rebelión de las masas (1930), La historia como sistema (1935), ¿Qué es filosofía? (póstuma) y Unas lecciones de metafísica (póstuma). 


\section{Aportaciones de Ortega y Gasset A LA PSICOLOGÍA}

Para Brachfeld (1936a [1970]), “falta aún un análisis concienzudo de las derivaciones para la psicología que nos brinda implícitamente el rico hontanar filosófico del pensamiento de Ortega y Gasset" (p. 506). Él recuerda las entrevistas con el filósofo español, que pusieron de manifiesto algunas analogías entre su psicología y la de Adler, así como su recomendación, que hizo posible que las primeras obras del psicoterapeuta austriaco se publicasen en España. Brachfeld hace referencia a una segunda entrevista con Ortega y Gasset, pero no dice la fecha en que tuvo lugar. Creemos que se produjo después de la publicación de la obra Goethe desde dentro (Ortega y Gasset, 1932). Brachfeld piensa que, aunque el filósofo nunca se haya dedicado a desarrollar con detalle sus ideas acerca de la psicología humana, casi todas sus obras son implícitamente una contribución al conocimiento del hombre.

Brachfeld considera que existen vocablos que se ponen en circulación bajo una firma conocida que los avala, lo que representa cierta garantía de su valor. Si decimos perspectivismo, sabemos perfectamente que ese concepto está garantizado por Ortega y Gasset. En nuestra opinión, en el "Prólogo-conversación" de Goethe desde dentro (1932), podemos apreciar la concepción del perspectivismo de Ortega y Gasset. En esta “conversación” entre Ortega y Gasset y Fernando Vela (18881966), secretario de redacción de la Revista de Occidente, el filósofo español expone la importancia que en la evolución literaria tiene el romanticismo, que es la rebelión del individuo contra los gremios.

Ortega y Gasset (1932 [2017]) analiza la influencia del romanticismo en la arquitectura, la escultura, el teatro y el cinematógrafo. Advierte que esta teoría no es una teoría independiente en su obra: "Es la teoría general de mi obra: el perspectivismo. Pero no es el 'punto de vista' en el sentido idealista, sino al revés: es que lo visto, la realidad, es también punto de vista" (p. 116).

Brachfeld propone que todas las ideas básicas de las teorías adlerianas se encuentran ya, en germen, en la obra de Pierre Janet (1859-1947). Adler nunca negó la influencia de las obras de Janet, y en varios de sus libros cita su nombre y su concepto de "sentimiento de incompletud". Cuando Janet habla de la "sobreestimación" y de la "subestimación" que caracterizan los estados delirantes, llega hasta el umbral de un sistema de "psicología estimativa", sin atreverse a franquear la entrada en esa tierra prometida.

Para Brachfeld, un primer intento en este sentido sería el conjunto de las teorías adlerianas. Considera que Ortega y Gasset y Max Scheler (1874-1928) habían entrevisto, en forma de observaciones filosóficas, la importancia de elaborar una disciplina de esta índole. Adler, un hombre un tanto limitado y sencillo, pero genial, realizó sin saberlo un viejo postulado que se remonta hasta Auguste Comte (1798-1857): "Partir decididamente en dos la psicología, estableciendo una zona inferior y otra superior" (Brachfeld, 1936a [1970], p. 117). La primera zona estaría dedicada a dilucidar problemas de "inspiración fisiológica", y la 
segunda estudiaría cuestiones que engendra el hecho de la consociación humana, de "inspiración sociológica".

Brachfeld considera que la mejor exposición católica de las teorías adlerianas es la obra Das Werden der sittlichen Person, de Rudolf Allers (1883-1963). Él piensa que las conferencias dadas por Allers en Madrid dejaron cierta huella en los Estudios sobre el amor de Ortega y Gasset. La obra de Adler es el primer intento de construir una psicología de la "estimación" de sí mismo y de los demás. "Doctrina postulada, con completa independencia de él, por Max Scheler, por Ortega y Gasset, y en el plano social y político, por Henri de Man” (Brachfeld, 1936a [1970], p. 160). De acuerdo con Brachfeld, la influencia de Adler sobre Ortega y Gasset fue muy profunda, aunque nadie la ha puesto de relieve, ni siquiera él mismo en la primera entrevista de 1931, dedicada a ciertas concordancias entre ambos autores, basada en las declaraciones del filósofo. La verdadera influencia de Adler sobre Ortega y Gasset parece haber empezado a partir de aquella entrevista.

La frase orteguiana "La vida nos está no impuesta, sino propuesta" parece una ingeniosa traducción al castellano, salvando hasta el retruécano del original: "Das Leben ist uns nicht gegeben, sondern aufgegeben! [Vivir es proyectarse]" (Brachfeld, 1936a [1970], p. 161). Para Brachfeld, todos los otros asertos de Ortega acerca de "la vida como proyecto" acusan la paternidad del Lebensplan [plan de vida] adleriano. Y "Yo soy yo y mi circunstancia" y el "perspectivismo" producen a menudo la impresión de haber sido inspiradas por la "ideología adleriana”. Sin embargo, Brachfeld (1936a [1970]) precisa que "el maestro español, siempre tan quisquilloso en cuanto a su 'originalidad' [...], sin duda no hubiera admitido estas 'influencias', que pueden probarse con los textos en la mano" (p. 161). Dice que en la entrevista Ortega y Gasset solo señalaba "concordancias" (como, por ejemplo, su idea de "vivir hacia el mundo").

Al analizar la obra Der Aufbau des Organismus, de Kurt Goldstein (18781965), destaca frases como "El tener un mundo circundante presupone, pues, siempre, cierta forma dada (Gegebenheit) del organismo; ¿cómo podría entonces estar determinado tan solo por este? El mundo circundante nace del 'mundo' a secas, tan solo cuando existe un organismo ordenado" (Brachfeld, 1936a [1970], p. 180). Brachfeld nos indica que advirtamos la concordancia del "mundo circundante" con el "Yo soy yo y mi circunstancia" de Ortega y Gasset.

Para examinar la envidia, los sentimientos de inferioridad y el problema de la autenticidad, Brachfeld cita una frase de Goethe: "Antes de querer hacer algo, es preciso ser algo". El estudio de los sentimientos de inferioridad nos lleva al problema señalado por Goethe, en torno al cual gravita una fuerte tendencia de la filosofía moderna. En filosofía se admite que el hombre existe, y que, además, es. Para Brachfeld, sería preciso que pudiera ser él mismo. Ese Selbst-Sein alemán podría traducirse por el término latino ipseidad. Su más hermosa y conocida expresión es la frase de Nietzsche (1844-1900): "Werde, der du bist! [¡Conviértete en lo que eres!]”. La frase de Ortega y Gasset: “iSeamos 
auténticos!", hace referencia al problema de la autenticidad.

\section{LOS SENTIMIENTOS DE INFERIORIDAD para Brachfeld}

En el preámbulo a la primera edición francesa (1939) y segunda edición española (1944) de Los sentimientos de inferioridad, Brachfeld expone que el "complejo" psicológico con el que se relacionan todos los fenómenos de la vida moderna merecería llamarse sencillamente complejo de Gulliver, y podría ser considerado como la esencia misma de la psicología del ser humano. Cada uno de nosotros es un Gulliver: cuando sufrimos la sensación opresora de nuestra impotencia y de nuestras flaquezas ante problemas que solo unos gigantes podrían resolver; en cambio, cuando leemos en el diario la noticia de un triunfo de nuestro equipo de fútbol, nos sentimos como el simpático gigante del país de Lilliput, salido de la imaginación de Jonathan Swift (1667-1745).

Todos vivimos bajo el signo de Gulliver. Brachfeld precisa que si tuviera que reprochar algo a Adler sería el no haber bautizado su sistema, la psicología comparada del individuo — nombre poco feliz, ya que provoca toda clase de equívocos-, sencillamente como psicosíntesis, y el complejo de inferioridad y superioridad, como complejo de Gulliver.

Para Brachfeld, existe otro motivo para invocar el nombre de Gulliver. Es una costumbre oponer al sentimiento de inferioridad el sentimiento o "complejo" de superioridad, el cual no es, en realidad, sino la mera consecuencia de aquel, y no su contrario.
El complejo de superioridad oculta, casi siempre, un sentimiento de inferioridad más profundo, ya que en el fondo es uno de sus síntomas. "Parece, pues, preferible abarcar bajo una denominación común ambos fenómenos tan íntimamente enlazados entre sí, y como símbolo de su unión nada parece más indicado que el nombre de Gulliver" (Brachfeld, 1936a [1970], p. 25).

La experiencia gulliveriana consiste esencialmente en un cambio de perspectiva: dicho cambio es inherente a toda la vida humana. Es, además, el objetivo de todo análisis psicológico, ya que se busca cambiar el punto de mira del enfermo. Por regla general, se trata de quitar importancia a todo cuanto el neurótico exagera y sobrestima como dificultad, y, por el contrario, magnificar el sentimiento del propio valor, si se posee en grado insuficiente o inadecuado. Cada biografía anímica de neuróticos es una verdadera novela, y estas novelas están llenas de situaciones "gulliverianas".

En el prólogo a la tercera edición española, Brachfeld dice que el hecho de que esta nueva edición en lengua española aparezca en la editorial Luís Miracle, de Barcelona, parece simplemente lógico. En esta editorial, se publicó en 1941 El sentido de la vida, de Adler, traducido por Brachfeld. No era la primera obra de Adler que aparecía en castellano, pero iba a ser la que llamaría más la atención. El psiquiatra y psicoanalista Ramón Sarró (1900-1993) escribió el prólogo.

Para Sarró, la psicología de Adler es la que más "conviene" al espíritu de los hispanos. Para Brachfeld, es una observación interesante, ya que Sarró se inclina más 
bien a la observancia freudiana, "hermana enemiga". No cabe la menor duda, puesto que el español oscila entre los polos opuestos de la autoestimación. Podría aplicársele muy bien los famosos versos de Goethe: "himmelhoch jauchzend, / zu Tode betrübt".

"O se desborda hasta el cielo, o se siente deprimido mortalmente" (Brachfeld, 1936a [1970], p. 10). Sin duda, para Brachfeld, este rasgo del carácter del peculiar ser de los hispanos, "audax Japheti genus", explica la buena acogida de una obra que intenta situar los fenómenos anímicos humanos, tanto individuales como colectivos, en torno al eje de los sentimientos de inferioridad y superioridad. La cuarta edición española fue publicada en 1970, cuando ya hacía tres años que había fallecido su autor.

\section{LOS SENTIMIENTOS DE INFERIORIDAD para Ortega y Gasset}

Brachfeld piensa que Ortega y Gasset sienta las bases para un análisis de la conducta basado en sentimientos autoestimativos. En 1923, en el primer número de la Revista de Occidente, el filósofo español publica el ensayo "Para una topografía de la soberbia española. Breve análisis de una pasión". En 1932, aparece de nuevo junto con otros ensayos en Goethe desde dentro. Para Brachfeld, Ortega y Gasset emite una teoría del sentimiento de inferioridad. Para este autor, la soberbia es nuestra pasión nacional. El hombre español es soberbio, infinitamente soberbio. Esta soberbia adquiere en algunas regiones peninsulares, sobre todo en Vasconia, formas extremas.Ortega y Gasset expone que su análisis puede servir de contribución para que un día se haga la topografía de la soberbia española, que se extiende por todo el territorio modulado en los giros más diversos: solo aparente en unas tierras, solo subterránea en otras. Y se pregunta: ¿qué es la soberbia?

El ingreso más fácil a la anatomía de la soberbia se obtiene partiendo de un fenómeno que, con mayor o menor frecuencia, se produce en todas las almas. Averigua un artista que otro se tiene o es tenido por superior a él. En algunos casos, tal averiguación no suscita en su interior ningún movimiento pasional. Esta superioridad sobre él que el prójimo se atribuye a sí mismo, u otros le reconocen, se encuentra como prevista en su ánimo; con más o menos claridad, se sentía de antemano inferior a aquel otro hombre. (Ortega y Gasset, 1923 [2017], pp. 174-175)

Para Ortega y Gasset, la valoración que el artista ahora encuentra declarada en el exterior coincide con la que, tal vez sin formular, existía dentro de sí. Pero, en otros casos, el efecto de esta averiguación es muy distinto. El hecho de que el otro artista se tenga o sea tenido en más que él produce una revolución en sus entrañas espirituales. La contradicción entre la que él cree su verdadera relación jerárquica y la que ve afirmada por los otros es tal que, si la aceptase, sería tanto como aceptar su propia anulación. La raíz misma de su individualidad sufre una herida que provoca un sacudimiento de toda la persona. Su energía espiritual se concentra como un ejército y ejecuta una íntima afirmación de sí mismo y de su derecho al rango disputado. 
Como los gestos que expresan las emociones son simbólicos, el individuo se yergue un poco mientras íntimamente reafirma su fe en que vale más que el otro. Al sentimiento de creerse superior al otro le acompaña una erección del cuello y la cabeza, que tiende a hacernos físicamente más altos que el otro. La emoción que se expresa en ese gesto es nombrada finamente altanería en castellano. Fácilmente reconoceremos en esta descripción lo que suele denominarse un movimiento de soberbia.

Se ve, pues, que Ortega y Gasset atribuye la soberbia a una reacción, a una disminución de nuestro ser - lo que corresponde exactamente a la voz empleada por los alemanes para esta clase de reacciones: MinderwertigkeitsGefühl (sentimiento de minusvalía)-, y a la amenaza de la opinión que acerca de nuestro propio valor hemos tenido. (Brachfeld, 1936a [1970], p. 508)

Brachfeld precisa que Ortega y Gasset explica muy bien la soberbia cuando dice que nuestro ánimo se revuelve y subleva contra una realidad que anula la estimación en que nosotros nos teníamos. Esa realidad nos parece fraudulenta, y con ese movimiento interior, tendemos a borrarla y corregirla, al menos en el ámbito de nuestra conciencia. Las conclusiones del filósofo español contienen el germen de toda una teoría psicológica, la misma que Adler desarrolla viniendo de otros páramos: los de la medicina y la psicoterapia. La descripción de la soberbia le proporciona a Ortega y Gasset la ventaja de situarse "inmediatamente ante la zona psíquica donde la soberbia brota. En efecto, esas íntimas sublevaciones del 'amor propio' nos revelan que en el último fondo de nuestra persona llevamos, sin sospecharlo, un complicadísimo balance estimativo" (Ortega y Gasset, 1923 [2017], p. 176).

Para Brachfeld, Pierre Janet llegó muy cerca de esta apreciación, pero nadie ha sabido dar tanta gracia y elegancia a la expresión de este pensamiento como Ortega y Gasset, que lleva más lejos su penetrante análisis:

Cuando arrojamos objetos de varia densidad en un líquido, quedan a poco colocados en distinto nivel. Esta localización resulta del dinamismo que unos sobre otros ejercen. Imagínese que los objetos gozasen de sensibilidad. Sentirían su propio esfuerzo, que los mantiene a mayor o menor altura; tendrían lo que podemos llamar un sentimiento del nivel. (Ortega y Gasset, 1923 [2017], p. 176)

Brachfeld dice que este sentimiento del nivel es el que da lugar a los sentimientos de inferioridad. Piensa que Ortega y Gasset llega al mismo resultado desde un punto de partida muy diferente de aquel del que parte la escuela adleriana. Para el filósofo español, entre los ingredientes que componen nuestro ser, el sentimiento del nivel es uno de los decisivos. Nuestro modo de comportarnos depende del nivel humano que nos atribuyamos. El carácter de una sociedad dependerá del modo de valorarse a sí mismos los individuos que la forman. "Por eso podría partir de aquí, mejor que de otra parte, una caracterología de los pueblos y razas" (Ortega y Gasset, 1923 [2017], p. 176). 
Ortega y Gasset (1923 [2017]) expone que hay dos maneras de valorarse a sí mismo radicalmente distintas. Hay hombres que se atribuyen un determinado valor, mirándose a sí mismos. Esta es una valoración espontánea. Hay otros que se valoran a sí mismos mirando a los demás y viendo el juicio que merecen. Esta es una valoración refleja. "Apenas habrá un hecho más radical en la psicología de cada individuo" (p. 176).

Para unos, lo decisivo es la estimación en que se tengan; para otros, la estimación en que sean tenidos. La soberbia solo se produce en individuos del primer tipo; la vanidad, en los del segundo. Ambas tendencias tienen dos sentimientos opuestos de gravitación psíquica. La psique que se valora de forma refleja pondera hacia los demás y vive de su periferia social. A la psique que se valora espontáneamente no le influyen las opiniones de los demás. Por esta razón, no cabe imaginar dos pasiones más antagónicas que la soberbia y la vanidad. "La vanidad es una pasión periférica que se instala en lo exterior de la persona, en tanto que el soberbio lo es en el postrer fondo de sí mismo" (Ortega y Gasset, 1923 [2017], p. 177).

Para Brachfeld, la autoestimación es un hecho eminentemente social. Solo puede brotar en sociedad, como resultante de la comparación con los demás, comparación que es inconsciente y poco violenta en el caso de la persona normal, y exagerada y enfermiza en el proceso de los sentimientos de inferioridad. A esto parece aludir Ortega y Gasset al decir que "el individuo se atribuye un rango en vista del que juzga corresponder al prójimo”. Brachfeld piensa que la soberbia queda equiparada o por lo menos aproximada a los resentimientos. Lo que Ortega y Gasset define como soberbia también es extensible al resentimiento, y se puede aplicar a lo que se oculta en el fondo de ambos: "el radical sentimiento de disminución de la personalidad, de menos valor, de insuficiencia e inferioridad" (Brachfeld, 1936a [1970], p. 511). Precisa que el hombre que se valora espontáneamente no tendrá en cuenta la valoración de los demás; pero esto no quiere decir que para valorarse no atienda a lo que valen los demás. La valoración espontánea puede ser humilde, justa, delicada y certera. El individuo se atribuye un rango en vista del que juzga corresponder al prójimo.

Al llegar a esta altura del análisis, divisamos con claridad lo que es la soberbia para Ortega y Gasset: un error por exceso en el sentimiento de nivel. Cuando este error es limitado y se reduce a nuestra relación jerárquica con los otros, no llega a colorear el carácter de la persona. Pone unos puntos de soberbia, pero no lo convierte en un hombre soberbio. Cuando el error es constante, el individuo vive en perpetuo desequilibrio de nivel, el gesto de engreimiento se hieratiza en la persona y le presta un hábito altanero.

La soberbia es una enfermedad de la función estimativa. El error persistente en nuestra propia valoración implica una ceguera para los valores de los demás. La función estimativa, encargada de percibir los valores que existen, se halla vuelta hacia el sujeto, que, incapaz de mirar en torno, no ve las cualidades del prójimo. No es que el soberbio se haga ilusiones 
sobre su propia excelencia, sino que a toda hora están patentes a su mirada los valores suyos, pero nunca los ajenos. No se puede curar la soberbia si se la trata como una ilusión, como una alucinación.

De acuerdo con Ortega y Gasset, lo contrapuesto a la soberbia es, más que la humildad, la abyección. El hombre abyecto es el que no se estima a sí mismo. Su función estimativa no percibe los valores ajenos a toda persona. No le podemos exigir dignidad de su conducta, ya que un acto digno le parecería un fraude, porque le invitaría a estimarse a sí mismo. La soberbia es oriunda de una ceguera psíquica para los valores humanos que no estén en el sujeto mismo.

La soberbia supone, para el filósofo, una psicología en que se da exagerada tendencia a gravitar la psique hacia dentro de sí misma, a bastarse a sí misma. Con agudo diagnóstico, se llama vulgarmente a la soberbia suficiencia. El soberbio se basta a sí mismo porque ignora lo ajeno. Los soberbios suelen ser herméticos, cerrados a lo exterior, sin curiosidad, que es una especie de porosidad mental. Temen morbosamente al ridículo. "Viven en perpetuo gesto anquilosado, ese gesto de gran señor, esa 'grandeza' que a los extranjeros maravilla siempre en la actitud del castellano y del árabe" (Ortega y Gasset, 1932 [2017], p. 178).

Ortega y Gasset (1932 [2017]) piensa que la raza española es misoneísta. Aceptar una novedad nos humillaría porque equivale a reconocer que antes no éramos perfectos, que fuera de nosotros quedaba aún algo bueno por descubrir. Al español castizo toda innovación le parece una ofensa: "Esto lo advertimos a toda hora los que nos esforzamos por refrescar un poco el repertorio de ideas alojadas en las cabezas peninsulares" (p. 178).

Para el filósofo, el análisis psicológico de este ensayo puede reducirse al siguiente

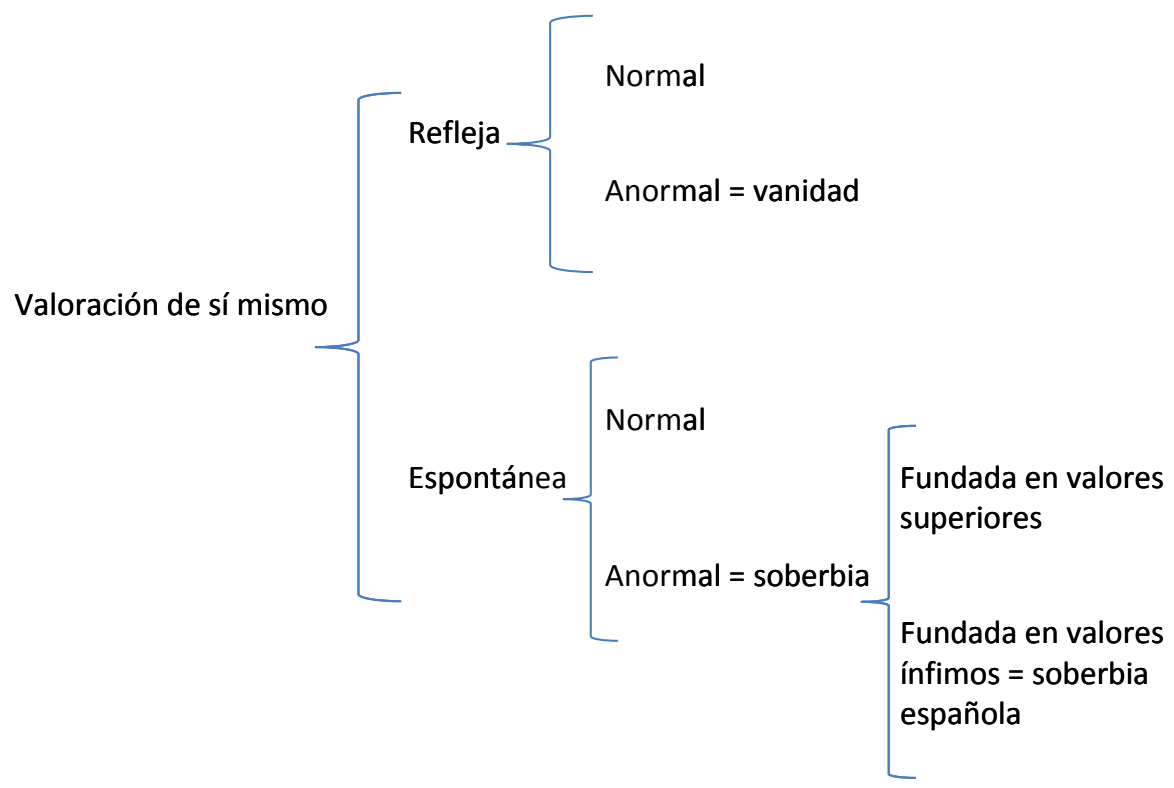


esquema de conceptos (Ortega y Gasset, 1932 [2017], p. 181):

Para Brachfeld (1936a [1970]), el análisis de Ortega y Gasset sobre la soberbia española confirma las apreciaciones de otros autores sobre el nil admirari español. Y precisa: "Lo que Ortega dice sobre las diversas fisonomías de la soberbia pertenece ya a nuestra obra en preparación $E l$ complejo de superioridad" (p. 512).

\section{LOS SENTIMIENTOS DE INFERIORIDAD- SUPERIORIDAD DE LOS CATALANES}

De acuerdo con Brachfeld, la pertenencia a una nación pequeña puede ser causa, a menudo, de complejos de inferioridadsuperioridad muy sui generis. Sin tener en cuenta este factor, es muy difícil comprender el fenómeno de los nacionalismos exacerbados de las pequeñas naciones, que propenden a considerarse como el ombligo del mundo y cultivan el etnocentrismo más exagerado y cándido. "Valdría la pena estudiar algún día el complejo de inferioridad de los catalanes, sumamente distinto del de otros pequeños pueblos, así como sus curiosas compensaciones ideológicas" (Brachfeld, 1936a [1970], p. 513). Los catalanes, durante mucho tiempo, se han sentido superiores a los demás pueblos de España a raíz de sus mayores realizaciones comerciales e industriales, aunque comparadas con las de otras naciones europeas no pasarían de ser mediocres.

Brachfeld propone que la importancia del separatismo catalán ha sido exagerada, ya que los separatistas no han constituido nunca más que una minoría, y las mejores mentes catalanas solo aspiraban a una $u$ otra forma de autonomía dentro de un sistema federal. Se podría escribir una historia desapasionada del catalanismo político, fenómeno típico y profundamente español, como ya lo intuyó Unamuno: "Era el resultado de una serie de malas inteligencias recíprocas entre castellans (españoles no catalanes) y catalans, agravada por la falta de la debida comprensión" (Brachfeld, 1936a [1970], p. 514).

Según Brachfeld (1936a [1970]), es psicológicamente comprensible el resentimiento anticentralista de los catalanes, de 1909 a 1936, contra el resto de España, y sobre todo contra Madrid, "que ni siquiera un Ortega y Gasset pareció haber comprendido, como lo comprendiera Unamuno, hombre a su vez de múltiples resentimientos muy hispánicos” (p. 514). Precisa que, al analizar el resentimiento catalán, Ortega y Gasset no emplea nunca la palabra resentimiento con acentos estimativos, sino tan solo como nombre de determinado fenómeno anímico, como una mera categoría psicológica y diagnóstica. Piensa que el catalanismo político, cuyo ciclo se cerró en 1936, fue un complicado, aunque en el fondo sencillo, fenómeno socioeconómicopsicológico, cuyo motor anímico era el resentimiento, engendrado por un violento complejo de inferioridad-superioridad. Las raíces psicológicas de este resentimiento "son las mismas que alimentaron, animan y alimentarán aún durante mucho tiempo la ideología de todos los pequeños pueblos" (Brachfeld, 1936a [1970], p. 515).

Brachfeld participó en el nacionalismo catalán durante su estancia en Barcelona. 
Ortega y Gasset había explicado cómo debía ser el Estado ideal. Su modelo de Estado territorial no tenía conciencia de la excepcionalidad de Cataluña ni del País Vasco. No fue él quien retiró sus propuestas, sino la política práctica. Brachfeld no cita ningún texto cuando habla de la incomprensión de Ortega y Gasset del fenómeno nacionalista catalán. Creemos que Brachfeld tiene en cuenta los discursos del filósofo español sobre el Estatuto de Cataluña en las Cortes Generales de 1931 y 1932.

Salvador de Madariaga (1886-1978), en 1953, criticó el apoyo de Brachfeld al nacionalismo catalán y expuso en una carta a la Revue de Psychologie des Peuples que los catalanes tenían un "sentimiento de superioridad" injustificado (Brachfeld, 1936a [1970], p. 515). Para Brachfeld, Madariaga no se da cuenta de que se trata de una "compensación" y no parece comprender que estos sentimientos están engendrados por un complejo de inferioridad-superioridad.

El 13 de mayo de 1932, Ortega y Gasset interviene en el debate sobre el Estatuto de Cataluña. Cuando defiende la idea de conllevancia, de adaptación resignada de dos sociedades, él "está en sintonía con el abogado catalán Amadeo Hurtado (1875-1950), que le ha escrito privadamente la misma idea de 'conllevarnos', y no está lejos de lo que cree Joan Estelrich (1896-1958)" (Gracia, 2014, p. 474).

María Zambrano (1904-1991) le confiesa a Ortega y Gasset que ha sentido una "emoción técnicamente religiosa", viéndole hablar desde la tribuna del Parlamento. Pero también manifiesta la decepción de lo que "hemos venido a ser" — una secta fiel a Ortega y Gasset - por haberlos educado él en la pureza de los ideales, casi todos perdidos en la insolidaridad y el desánimo, como le sucede a ella (Gracia, 2014, p. 474). Zambrano cree que está inhabilitada precisamente por culpa del filósofo, al fijar unas posiciones ideales que no se corresponden con la realidad política.

Manuel Azaña (1880-1940) observó lo mismo en una larguísima entrevista con Ortega y Gasset, en junio de 1932, para atraerlo a sus posiciones sobre el Estatuto de Cataluña.

Pero ha sido imposible, Ortega tiene un fondo provinciano invariable. Se forma de la política una idea como la del doctor Faustino antes de salir de su pueblo, como si el principio teórico fuese inflexible ante la complicación negociadora y tacticista de la política. (Gracia, 2014, p. 474)

\section{Observaciones finales}

Estamos de acuerdo con Mestre y Carpintero (1988) cuando afirman que tiene singular interés la actitud fuertemente positiva de Ortega y Gasset respecto de las tesis de Adler, y ello resulta aún más significativo cuando se conoce su recelo respecto de las ideas de Freud. Ortega y Gasset expuso la sustancial coincidencia de su pensamiento con las líneas centrales de la psicología de Adler en la entrevista que le hizo Brachfeld (1931) para la revista de psicología adleriana.

Brachfeld hace referencia a una segunda entrevista con Ortega, pero no dice cuándo se produjo. Creemos que tuvo lugar después de la publicación, en 1932, de la obra 
Goethe desde dentro. En 1936, aparece la primera edición de los Sentimientos de inferioridad, de Brachfeld. En las sucesivas ediciones de esta obra hemos visto la recepción del pensamiento del filósofo español.

Brachfeld expone que casi todas las obras de Ortega y Gasset son implícitamente una contribución al conocimiento del hombre y destaca el perspectivismo para analizar los problemas psicológicos. Sus conclusiones contienen el germen de una teoría psicológica. Brachfeld piensa que Ortega y Gasset y Max Scheler habían entrevisto, en forma de observaciones filosóficas, la importancia de una psicología estimativa. La psicología de la estimación fue formulada, en completa independencia de Adler, por ambos autores. Ortega y Gasset publicó en la Revista de Occidente el ensayo "Max Scheler. Un embriagado de esencias" (1928 [2017]), donde señala que Scheler ha sido el pensador por excelencia de nuestra época, caracterizada por el descubrimiento de las esencias.

De acuerdo con Brachfeld, las conferencias dadas por Rudolf Allers en Madrid dejaron cierta huella en los Estudios sobre el amor, de Ortega y Gasset. Los capítulos de esta obra fueron publicados por primera vez como folletones en el diario El Sol, de Madrid, en 1926 (Ortega y Gasset, 1926 [2017]), donde analiza el amor en Stendhal. Para Ortega y Gasset, Stendhal tenía la cabeza llena de teorías, pero carecía de dotes de teorizador. Piensa que se parece a Pío Baroja, que sobre los asuntos humanos reacciona primero de forma doctrinal. Uno y otro, mirados sin la oportuna cautela, ofrecen el aspecto de filósofos descarriados de la literatura. Y son todo lo contrario.
Basta con advertir que ambos poseen una abundante colección de teorías.

Para Brachfeld, las frases de Ortega y Gasset: "La vida nos está no impuesta, sino propuesta" y "La vida como proyecto" acusan la paternidad del "plan de vida adleriano". Y "Yo soy yo y mi circunstancia", el "perspectivismo", etcétera, producen la impresión de haber sido inspirados por la ideología adleriana. Brachfeld dice que en las entrevistas Ortega y Gasset solo aceptaba "concordancias" (como, por ejemplo, su idea de "vivir hacia el mundo"). En nuestra opinión, las frases de Ortega y Gasset no están inspiradas en la ideología adleriana.

Brachfeld nos pide que advirtamos la coincidencia entre "el mundo circundante" de Kurt Goldstein (1878-1965) y "Yo soy yo y mi circunstancia" de Ortega y Gasset. En nuestra opinión, la reflexión orteguiana sobre el yo y la circunstancia, que expone en Meditaciones del Quijote (1914), desarrollaba una intuición antigua, apuntada en la "Pedagogía del paisaje" de 1906 y ampliada en una conferencia del Ateneo de Madrid de 1915. Contra el criterio darwinista de que el hombre está sujeto a una ley superior de adaptación al medio, sin demasiado lugar para la libertad ni para la imaginación, Ortega y Gasset defiende el criterio inverso, sobre todo porque "hoy toma la ciencia un cariz más agradable y más risueño" (Gracia, 2014, p. 204).

Brachfeld piensa que, en el ensayo "Para una topografía de la soberbia española", Ortega y Gasset establece las bases para el análisis de una conducta a partir de los sentimientos autoestimativos y emite una teoría del sentimiento de inferioridad. 
Según Brachfeld, el filósofo español atribuye la soberbia a una reacción, a una disminución de nuestro ser, y la explica muy bien cuando dice que nuestro ánimo se revuelve y subleva contra una realidad que anula la estimación en que nosotros nos teníamos.

Para Ortega y Gasset y Brachfeld, el sentimiento de nivel da lugar a los sentimientos de inferioridad. Pero Brachfeld considera que lo que Ortega y Gasset define como soberbia también es extensible al resentimiento, y se puede aplicar a lo que se oculta en el fondo de ambos: el radical sentimiento de disminución de la personalidad.

Ortega y Gasset expone que hay dos maneras de valorarnos radicalmente distintas: la valoración espontánea y la valoración refleja. Para unos, lo decisivo es la estimación en que se tengan; para otros, la estimación en que sean tenidos. La soberbia se produce en los individuos del primer grupo; la vanidad, en los del segundo. No cabe imaginar dos pasiones más antagónicas que la soberbia y la vanidad. La vanidad se instala en lo exterior de la persona y la soberbia en el fondo de sí mismo.

\section{REFERENCIAS}

Adler, A. (1936). El problema del homosexualismo y otros estudios sexuales. Barcelona: Apolo.

Adler, A. (1941). El sentido de la vida. Nuevas perspectivas de la psicología individual. Barcelona: Luís Miracle.

Bernard, F. (1949). La psicología y sus aplicaciones. Barcelona: Olivér Brachfeld.

Brachfeld, O. (1936a [1970]). Los sentimientos de inferioridad. Barcelona: Luís Miracle.

Brachfeld, O. (1936b). El examen de la inteligencia de los niños. Gerona: Dalmau Carles Pla.

Brachfeld, O. (1949a). Los complejos de inferioridad de la mujer. Introducción a la psicología femenina. Barcelona: Horta.

Brachfeld, O. (1949b). Cómo interpretar los sueños. Barcelona: José Janés.

Brachfeld, O. (s. f.). La psicología del individuo y la comunidad de Alfred Adler. Archivo de Olivér Brachfeld.

Carrard, A. (1946). Psicología del jefe. Su formación y su misión. Barcelona: Victoria.

Gracia, J. (2014). José Ortega y Gasset. Madrid: Taurus.

Jung, C. G. (1935). Teoría del psicoanálisis. Barcelona: Apolo.

León, R. (1997). Rumbo al Nuevo Mundo: cuatro psicólogos de Europa Oriental en la historia de la psicología de América del Sur. Revista Latinoamericana de Psicología, 29(1), 9-34. 
León, R. (2000). Los psicólogos hispanohablantes y la teoría de Alfred Adler en la revista Internationale Zeitschrift für Individual Psychologie (1914-1937). Revista Latinoamericana de Psicología, 32(1), 107-126.

Mestre, M. V., y Carpintero, H. (1988). Unas notas sobre la entrada de Adler en España. Revista de Historia de la Psicología, 9(1), 47-62.

Ortega y Gasset, J. (1923 [2017]). Para una topografía de la soberbia española. En Obras completas (tomo V, pp. 174-181). Madrid: Taurus.

Ortega y Gasset, J. (1926 [2017]). Amor en Stendhal. En Obras completas (tomo V, pp. 463495). Madrid: Taurus.

Ortega y Gasset, J. (1928 [2017]). Max Scheler. Un embriagado de esencias. En Obras completas (tomo V, pp. 216-220). Madrid: Taurus.

Ortega y Gasset, J. (1932 [2017]). Prólogo-conversación. En Obras completas (tomo V, pp. 109-119). Madrid: Taurus. 
